\title{
Correction: Speech and language phenotype in Phelan-McDermid (22q13.3) syndrome
}

\author{
Amanda Brignell • Conway Gu • Alison Holm • Bronwyn Carrigg • Daisy A. Sheppard • David J. Amor • \\ Angela T. Morgan (D)
}

Published online: 15 March 2021

(c) The Author(s), under exclusive licence to European Society of Human Genetics 2021

Correction to: European Journal of Human Genetics https://doi.org/10.1038/s41431-020-00761-1

In the text of the original article linked to this correction article, we the authors incorrectly wrote "receptive" which has been changed to:

Revised text (page 8 of the online PDF):
Association between deletion size and language phenotype.

There was a strong association between deletion size and expressive language raw scores (co-efficient: $-1.57,95 \%$ CI: -3.2 to $0.08, \mathrm{p}=0.061$ ): as deletion size increased, expressive language scores decreased.

This has now been corrected in both the PDF and HTML versions of this article. 